\title{
On the atomic structure of $\mathrm{Zr}_{60} \mathrm{Cu}_{20} \mathrm{Fe}_{20}$ metallic glass
}

\author{
I Kaban ${ }^{1}$, P Jóvári ${ }^{2}$, M Stoica ${ }^{1}$, N Mattern ${ }^{1}$, J Eckert ${ }^{1, \#}$, W Hoyer ${ }^{3}$, B Beuneu ${ }^{4}$ \\ ${ }^{1}$ IFW Dresden, Institute for Complex Materials, P.O. Box 270116, D-01171 Dresden, Germany \\ ${ }^{2}$ Research Institute for Solid State Physics and Optics, H-1525 Budapest, POB 49, Hungary \\ ${ }^{3}$ Institute of Physics, Chemnitz University of Technology, D-09107 Chemnitz, Germany \\ ${ }^{4}$ Laboratoire Léon Brillouin, CEA-Saclay 91191 Gif sur Yvette Cedex France \\ ${ }^{\#}$ Also at TU Dresden, Institute of Materials Science, D-01062 Dresden, Germany \\ E-mail: i.kaban@ifw-dresden.de
}

\begin{abstract}
The structure of $\mathrm{Zr}_{60} \mathrm{Cu}_{20} \mathrm{Fe}_{20}$ metallic glass has been studied with high-energy $\mathrm{x}$-ray diffraction, neutron diffraction and extended x-ray absorption spectroscopy and modelled with the reverse Monte-Carlo simulation technique. It is found that $\mathrm{Cu}$ and $\mathrm{Fe}$ atoms prefer $\mathrm{Zr}$ as a nearest neighbour. The mean interatomic distance between $\mathrm{Cu} / \mathrm{Fe}$ and $\mathrm{Zr}$ atoms in the glass is remarkably shorter than the sum of the respective atomic radii. The coordination numbers for $\mathrm{Cu} / \mathrm{Fe}-\mathrm{Cu} / \mathrm{Fe}$ pairs are very close to each other suggesting a regular distribution of $\mathrm{Cu}$ and $\mathrm{Fe}$ atoms in the $\mathrm{Zr}_{60} \mathrm{Cu}_{20} \mathrm{Fe}_{20}$ metallic glass.
\end{abstract}

PACS numbers: 61.43.Dq, 61.05.cp, 61.05.fm, 61.05.cj

\section{Introduction}

Glass formation in the $\mathrm{Cu}-\mathrm{Fe}-\mathrm{Zr}$ ternary system and in the $\mathrm{Zr}_{60} \mathrm{Cu}_{20} \mathrm{Fe}_{20}$ alloy in particular has been studied earlier [1-4]. The $\mathrm{Zr}_{60} \mathrm{Cu}_{20} \mathrm{Fe}_{20}$ composition is important because it provides a base for the quaternary bulk metallic glasses in the $\left(\mathrm{Zr}_{x} \mathrm{Cu}_{100-x}\right)_{0.8}\left(\mathrm{Fe}_{40} \mathrm{Al}_{60}\right)_{0.2}$ system reported recently [5]. These glasses are interesting for biomedical applications, for example as implants. The interest in this system is also caused by the principal difference between the binary system $\mathrm{Cu}-\mathrm{Fe}$ and the other two systems $(\mathrm{Cu}-\mathrm{Zr}$ and $\mathrm{Fe}-\mathrm{Zr}$ ) limiting the concentration triangle $\mathrm{Cu}-\mathrm{Fe}-\mathrm{Zr}$. The binary systems $\mathrm{Cu}-\mathrm{Zr}$ and $\mathrm{Fe}-\mathrm{Zr}$ are characterized by a negative heat of mixing and formation of a series of binary compounds and eutectic alloys in the crystalline state [6,7]. Both $\mathrm{Cu}-\mathrm{Zr}$ and $\mathrm{Fe}-\mathrm{Zr}$ binary systems demonstrate a high glass-forming ability [8-13]. In contrast, the heat of mixing of the $\mathrm{Cu}-\mathrm{Fe}$ binary system is positive and the mutual solubility of $\mathrm{Cu}$ and $\mathrm{Fe}$ is very low in the solid state [6,7]. There is a liquid-liquid miscibility gap in the supercooled $\mathrm{Cu}-\mathrm{Fe}$ liquids [14]. Cu-Fe alloys show almost zero glass-forming ability. Formation of an amorphous phase has only been reported for the thin $\mathrm{Cu}-\mathrm{Fe}$ films (about 60 $\mathrm{nm}$ thickness) upon application of high energy (300 keV) ion mixing [15].

Inoue et al [1] found that there is a two-stage endothermic reaction for $\mathrm{Zr}_{70}(\mathrm{Cu}-\mathrm{Fe})_{30}$ metallic glasses upon annealing at temperatures below the glass transition temperature $T_{\mathrm{g}}$. This was explained 
by the difference in the bonding among the constituent elements and the differences in the atomic rearrangements by the structural relaxation. The low-temperature endothermic peak was attributed to local and medium-range rearrangements of $\mathrm{Cu}$ and $\mathrm{Fe}$ atoms with weak bonding, while the hightemperature endothermic reaction was related to the long-range co-operative regroupings of $\mathrm{Cu}-\mathrm{Zr}$ and Fe-Zr pairs.

Michaelsen et al [2] studied Zr-rich $\mathrm{Zr}_{100-\mathrm{x}}(\mathrm{Cu}-\mathrm{Fe})_{\mathrm{x}}(24 \leq \mathrm{x} \leq 50)$ metallic glasses with different $\mathrm{Cu}-\mathrm{Fe}$ ratio by means of Mössbauer spectroscopy. Based on the analysis of the experimental spectra it was suggested that $\mathrm{Fe}$ atoms prefer $\mathrm{Zr}$ as nearest neighbours similar to the short-range ordering in the binary $\mathrm{Zr}_{2} \mathrm{Fe}$ amorphous phase, i.e. in other words, $\mathrm{Fe}$ was concluded to not substitute for $\mathrm{Cu}$ isostructurally in the Zr-rich ternary glasses. Zhou et al [3] observed that X-ray photoelectron spectra (XPS) of ternary $\mathrm{Zr}_{76}\left(\mathrm{Fe}_{\mathrm{x}} \mathrm{Cu}_{1-\mathrm{x}}\right)_{24}$ metallic glasses can be roughly decomposed into two independent contributions from the state of the respective binary metallic glasses $\mathrm{Zr}-\mathrm{Fe}$ and $\mathrm{Zr}-\mathrm{Cu}$, which might be interpreted as an evidence of phase separation in the ternary $\mathrm{Zr}-\mathrm{Cu}-\mathrm{Fe}$ metallic glasses. However, it was also found in [3] that the shift of the binding energy of the $\mathrm{Cu} 2 \mathrm{p}_{3 / 2}$ core level in $\mathrm{Zr}-\mathrm{Cu}-\mathrm{Fe}$ glasses increases with decreasing $\mathrm{Cu}$ concentration, which is opposite to what was observed for binary $\mathrm{Zr}-\mathrm{Cu}$ glasses. Therefore, it can be supposed that the chemical environment around atoms in the ternary $\mathrm{Zr}-\mathrm{Cu}-\mathrm{Fe}$ metallic glasses differs from those in the $\mathrm{Zr}$-rich binary $\mathrm{Zr}-\mathrm{Cu}$ and $\mathrm{Zr}-\mathrm{Fe}$ glasses.

In order to elucidate how the differences in bonding forces between $\mathrm{Cu}, \mathrm{Fe}$ and $\mathrm{Zr}$ atoms in the corresponding pairs are reflected in the local atomic ordering in the ternary $\mathrm{Zr}-\mathrm{Cu}-\mathrm{Fe}$ metallic glasses, the six partial pair distribution functions should be known. In the present work, we investigate the $\mathrm{Zr}_{60} \mathrm{Cu}_{20} \mathrm{Fe}_{20}$ metallic glass with the X-ray diffraction (XRD), neutron diffraction (ND) and extended $\mathrm{X}$-ray absorption fine structure (EXAFS) experiments and model its structure with the reverse Monte Carlo (RMC) simulation method. Simultaneous modelling of the four experimental datasets allows to obtain partial pair distribution functions and to extract information on the short-range atomic order in the $\mathrm{Zr}_{60} \mathrm{Cu}_{20} \mathrm{Fe}_{20}$ metallic glass.

\section{Experimental}

A master alloy with nominal composition $\mathrm{Zr}_{60} \mathrm{Cu}_{20} \mathrm{Fe}_{20}$ was prepared by arc melting of a mixture of pure $\mathrm{Cu}$ (99.99\%), $\mathrm{Fe}$ (99.95\%), and $\mathrm{Zr}$ (99.96\%) under a Ti-gettered $\mathrm{Ar}$ atmosphere. The alloy ingot was re-melted several times to ensure homogeneity. Amorphous ribbons (width of $4 \mathrm{~mm}$, thickness of about $20 \mu \mathrm{m}$ ) were obtained by single-roller melt spinning on a copper wheel under Ar flow at $24 \mathrm{~ms}^{-1}$ tangential wheel velocity.

The x-ray diffraction experiment was performed at the BW5 beamline [16] at HASYLAB (DESY, Hamburg, Germany) with an energy of the incident beam of $100 \mathrm{keV}$. The scattered intensity 
was recorded by a Ge solid-state detector. The raw data were corrected for background, polarization, detector dead-time and variations in detector solid angle [17].

The neutron diffraction measurement was carried out with the 7C2 diffractometer at the Léon Brillouin Laboratory (CEA-Saclay, France). The wavelength of the incident radiation was $0.73 \AA$. Pieces of amorphous ribbons were filled into a thin-walled $(0.1 \mathrm{~mm})$ vanadium container of $7 \mathrm{~mm}$ diameter. The raw data were corrected for the detector efficiency and background scattering. Attenuation due to the sample absorption was estimated according to [18].

The EXAFS measurements at the $\mathrm{Cu}$ and $\mathrm{Fe} K$-absorption edges were carried out at the HASYLAB beamline $X$ [16]. The spectra were collected in the transmission mode using fixed exit double-crystal $\mathrm{Si}(111)$. The intensities before and after the sample as well as after the reference samples were recorded by three ionization chambers filled with a mixture of $\operatorname{Ar} / \mathrm{N}_{2}(\sim 10 \%$ absorption), $\operatorname{Ar}(\sim 50 \%$ absorption) and $\operatorname{Kr}(\sim 100 \%$ absorption), respectively. The x-ray absorption cross sections $\mu(E)$ were converted to $\chi(k)$ by standard procedures of data reduction using the program VIPER [19].

The experimental XRD and ND structure factors as well as $k^{3}$ weighted EXAFS $\chi(k)$ curves are shown in Fig. 1.

\section{Results and discussion}

The reverse Monte Carlo simulation technique [20,21] has been successfully applied in a number of studies carried out on liquid and amorphous alloys. In this method, large-scale atomic models compatible (within experimental uncertainty) with experiments and physical constraints (e.g. density, coordination constraints) are generated (for details, see for example [11,21-24]). In the present work, the rmc ++ program $[21,25]$ has been used. The simulation box contained 24000 atoms with the proper stoichiometry. The number density of the system was $54.16 \mathrm{~nm}^{-3}$ calculated from the mass density $7.07 \mathrm{~g} / \mathrm{cm}^{3}$. EXAFS backscattering coefficients needed to obtain the model $\chi(k)$ functions were calculated by the FEFF8.4 program [26].

Four structural models have been tested for the $\mathrm{Zr}_{60} \mathrm{Cu}_{20} \mathrm{Fe}_{20}$ metallic glass. In Model 1, it was supposed that $\mathrm{Zr}, \mathrm{Cu}$ and $\mathrm{Fe}$ atoms can be bonded in any proportion, i.e. no restrictions on the topological and chemical order were used. In this model, the following minimum interatomic distances (cut offs) were applied: $r_{Z r Z r}^{\min }=2.8 \AA, r_{Z r C u}^{\min }=r_{Z r F e}^{\min }=2.4 \AA, r_{C u C u}^{\min }=2.2 \AA, r_{C u F e}^{\min }=2.2 \AA, r_{F e F e}^{\min }=2.1$

$\AA$. In the next two models, the possibility of demixing in the $\mathrm{Zr}_{60} \mathrm{Cu}_{20} \mathrm{Fe}_{20}$ glass was checked. In the Model 2, a coordination constraint prohibiting some part of $\mathrm{Zr}$ atoms to have simultaneously $\mathrm{Cu}$ and $\mathrm{Fe}$ nearest neighbours was applied. In the Model 3, formation of $\mathrm{Cu}-\mathrm{Fe}$ pairs was completely forbidden by increasing the $\mathrm{Cu}-\mathrm{Fe}$ cut off up to $3.1 \AA$. Finally, in the Model 4, a coordination constraint determining that $\mathrm{Fe}$ atoms are coordinated only by $\mathrm{Zr}$ atoms was used (that is, besides Fe$\mathrm{Cu}, \mathrm{Fe}-\mathrm{Fe}$ pairing was also forbidden). 
Initial configurations were obtained by putting atoms randomly in the simulation box. In the next step, the atoms were moved around to satisfy the cut offs. Then the experimental diffraction datasets were fitted and coordination constraints were introduced if needed. The EXAFS spectra were added only in the final step. An important difference of diffraction and EXAFS is that the latter is a short range order technique insensitive to long range order fluctuations (and density). For this reason, if fitted simultaneously, it usually happens that convergence is already reached for EXAFS while the fit of diffraction datasets is still poor. Thus, some time can be saved if only diffraction data are fitted first (together with coordination constraints which may also influence long range order); EXAFS measurements are added if diffraction data are well reproduced and coordination constraints are satisfied.

A new feature of the rmc++ program $[21,25]$ is the possibility of swapping two atoms at an arbitrary separation. Such moves are especially useful if there are long range correlations in the system or the packing fraction is high hindering the move of atoms. Swap moves were used in all simulation runs.

Some test runs were also carried out in this work to judge the relative importance of each experimental dataset. It was found that $\mathrm{Zr}-\mathrm{Zr}$ and $\mathrm{Zr}-(\mathrm{Cu}, \mathrm{Fe})$ correlations can only be reliably separated if both diffraction datasets are fitted. To resolve $\mathrm{Zr}-\mathrm{Cu}$ and $\mathrm{Zr}$-Fe correlations it was necessary to fit both EXAFS datasets.

As an example, the model curves obtained by the Model 1 are compared with the experimental data in Fig. 1. It should be noted that similar quality fits were obtained also for the Model 2 and Model 3. The quality of the fits became remarkably worse for the Model 4 (not shown); therefore this model assuming that $\mathrm{Fe}$ atoms are bonded only to $\mathrm{Zr}$ atoms can be omitted from further discussion.

Figure 2 compares the partial pair distribution functions $g_{\mathrm{ij}}(r)$ for the $\mathrm{Zr}_{60} \mathrm{Cu}_{20} \mathrm{Fe}_{20}$ metallic glass obtained with the Models 1-3. It can be seen that the $\mathrm{Cu}-\mathrm{Cu}, \mathrm{Cu}-\mathrm{Fe}$ and $\mathrm{Fe}-\mathrm{Fe}$ partial pair distribution functions get an unusual shape if $\mathrm{Cu}-\mathrm{Fe}$ bonds are forbidden. They do not oscillate around unity. Therefore, the Model 3 prohibiting direct $\mathrm{Cu}-\mathrm{Fe}$ bonding does not look as a plausible one. A similar behaviour of the $\mathrm{Cu}-\mathrm{Cu}, \mathrm{Cu}-\mathrm{Fe}$ and $\mathrm{Fe}-\mathrm{Fe}$ partial pair distribution functions has been observed for the Model 2 upon strengthening of the coordination constraint that forced a part of the $\mathrm{Zr}$ atoms to have only $\mathrm{Cu}$ or $\mathrm{Fe}$ nearest neighbours. It is seen that already for $20 \%$ constraint, the $\mathrm{Cu}-\mathrm{Fe}$ pair distribution function turns somewhat below the unity line, while the $\mathrm{Fe}-\mathrm{Fe}$ pair distribution function goes above the unity line. Hence, if there is a tendency of separation of $\mathrm{Cu}$ and $\mathrm{Fe}$ atoms in the $\mathrm{Zr}_{60} \mathrm{Cu}_{20} \mathrm{Fe}_{20}$ metallic glass, it is rather weak. Much more plausible is the Model 1, which enables all atomic bonds in the simulation box.

The nearest neighbour distances $r_{\mathrm{ij}}$ (uncertainty of about $0.02 \AA$ ) and the coordination numbers $N_{\mathrm{ij}}$ (uncertainty of about 10\%) extracted from the Model 1 and Model 2 are listed in Table 1. As the difference between the coordination numbers corresponding to these models is rather small, only Model 1 is further discussed. The mean interatomic distances $r_{\mathrm{ZrFe}}(2.67 \AA)$ and $r_{\mathrm{ZrCu}}(2.78 \AA)$ in the 
$\mathrm{Zr}_{60} \mathrm{Cu}_{20} \mathrm{Fe}_{20}$ metallic glass are remarkably shorter than the respective sums of the Goldschmidt atomic $\operatorname{radii}\left(r_{\mathrm{ZrFe}}=2.841 \AA\right.$ and $r_{\mathrm{ZrCu}}=2.878 \AA$ [27] $)$. The same conclusion was made in the recent work of Michalik et al [27] who studied $\mathrm{Zr}_{60} \mathrm{Cu}_{20} \mathrm{Fe}_{20}$ metallic glass by using X-ray diffraction (XRD) technique. Their analysis of the total radial distribution function revealed that the $\mathrm{Zr}-\mathrm{Fe}$ and $\mathrm{Zr}-\mathrm{Cu}$ interatomic distances in the glass are significantly shorter than the respective sums of the nominal atomic radii and than the interatomic distances in the crystalline state. It has also been established in other studies that the bond lengths between atoms of different type (e.g. metal and transition metal (TM), metal-semimetal) are significantly shorter in liquid or amorphous alloys as compared to their crystalline counterparts or the arithmetic sum of the respective atomic radii (see, for example, references 10,22,23). The strong affinity between $\mathrm{Zr}$ and $\mathrm{TM}$ atoms correlates with the enthalpy of mixing in the $\mathrm{Zr}-\mathrm{Cu}$ and $\mathrm{Zr}-\mathrm{Fe}$ binary systems [7]. The $\mathrm{Cu}-\mathrm{Cu}, \mathrm{Cu}-\mathrm{Zr}$ and $\mathrm{Zr}-\mathrm{Zr}$ interatomic distances in the ternary $\mathrm{Zr}_{60} \mathrm{Cu}_{20} \mathrm{Fe}_{20}$ glass agree with those in the binary $\mathrm{Zr}_{65} \mathrm{Cu}_{35}$ glass [11] (Table 1). The mean $\mathrm{Cu}-\mathrm{Cu}(2.60 \AA)$ and $\mathrm{Fe}-\mathrm{Fe}(2.53 \AA)$ distances in the glassy $\mathrm{Zr}_{60} \mathrm{Cu}_{20} \mathrm{Fe}_{20}$ are shorter than those in the crystalline $\mathrm{Zr}_{60} \mathrm{Cu}_{20} \mathrm{Fe}_{20}$ (2.64 and $2.68 \AA$ respectively [27]). This can be explained by densification of the atomic packing in the amorphous state.

It follows from the Model 1 that $\mathrm{Cu}$ and $\mathrm{Fe}$ atoms are bonded to $\mathrm{Zr}$ atoms in approximately equal proportion $\left(N_{\mathrm{ZrCu}}=2.3, N_{\mathrm{ZrFe}}=2.0\right)$. The mean coordination numbers for $\mathrm{Cu} / \mathrm{Fe}-\mathrm{Cu} / \mathrm{Fe}$ pairs are very close to each other $\left(N_{\mathrm{ij}} \approx 2\right.$ for $\left.\mathrm{i}, \mathrm{j}=\mathrm{Cu}, \mathrm{Fe}\right)$ suggesting an even distribution of $\mathrm{Cu}$ and $\mathrm{Fe}$ atoms in the $\mathrm{Zr}_{60} \mathrm{Cu}_{20} \mathrm{Fe}_{20}$ metallic glass on the large scale.

\section{Conclusions}

Four experimental datasets obtained for $\mathrm{Zr}_{60} \mathrm{Cu}_{20} \mathrm{Fe}_{20}$ metallic glass (XRD, ND and EXAFS at $\mathrm{Cu}$ and Fe K-edges) were modelled simultaneously by the means of the reverse Monte Carlo simulation technique. Four different models have been tested. The model assuming an even distribution of the constituent atoms in the glass seems to be the most plausible. It is found that $\mathrm{Cu}$ and $\mathrm{Fe}$ atoms prefer $\mathrm{Zr}$ as nearest neighbours. They are bonded to $\mathrm{Zr}$ atoms in approximately equal proportion. The mean interatomic distance between $\mathrm{Cu} / \mathrm{Fe}$ and $\mathrm{Zr}$ atoms in the $\mathrm{Zr}_{60} \mathrm{Cu}_{20} \mathrm{Fe}_{20}$ metallic is remarkably shorter than the sum of the respective atomic radii. Almost all interatomic distances in the glassy state are shorter than those in crystalline $\mathrm{Zr}_{60} \mathrm{Cu}_{20} \mathrm{Fe}_{20}$. The strong affinity between $\mathrm{Zr}$ and $\mathrm{Cu} / \mathrm{Fe}$ atoms correlates with the enthalpy of mixing in the $\mathrm{Zr}-\mathrm{Cu}$ and $\mathrm{Zr}$-Fe binary systems.

\section{Acknowledgment}

I. Kaban acknowledges Deutsches Elektronen-Synchrotron DESY (Hamburg, Germany) for the support of experiments performed at HASYLAB. P. Jóvári was supported by the Bolyai Research Fellowship of the Hungarian Academy of Sciences. 


\section{References}

[1] Inoue A, Masumoto T and Chen H S 1985 J. Mater. Sci. 204057

[2] Michaelsen C, Meyer M and Freyhardt H C 1990 J. Appl. Phys. 68269

[3] Zhou X Y, He Z He and Zhang Q R 1997 J. Phys.: Condens. Matter 94139

[4] Wang T L and Li B X 2009 J. Alloys and Comp. 481156

[5] Jin K and Löffler J F 2005 Appl. Phys. Lett. 86241909

[6] Massalski T B, Okamoto H, Subramanian P R and Kacprzak L (ed) 1990 Binary Alloy Phase diagrams (Materials Park, Ohio: ASM International)

[7] De Boer F R, Boom R, Mattens W C M, Miedema A R and Niessen A R 1989 Cohesion in Metals: Transition Metal Alloys (North-Holland Physics Publishing, Amsterdam, 1989)

[8] Ray R, Giessen B C and Grant N J 1968 Scripta Metall. 2359

[9] Altounian Z, Guo-Hua T, Strom-Olsen J O 1982 J. Appl. Phys. 534755

[10] Buschow K H J 1984 J. Phys. F : Met. Phys. 14593

[11] Mattern N, Jóvári P, Kaban I, Gruner S, Elsner A, Kokotin V, Franz H, Beuneu B and Eckert J 2009 J. Alloys and Comp. 485163

[12] Masumoto T, Ohnuma S, Shirakawa K, Nose M and Kobayashi K 1980 J. Phys. Colloq. 41686

[13] Buschow K H J, Vincze I, van der Woude F 1983 J. Non-Cryst. Solids 54101

[14] Nakagawa Y 1958 Acta Metall. 6704

[15] Huang L J, Liu B X and Li H D 1987 Appl. Phys. A: Solids Surf. 44269

[16] http://www.hasylab.de

[17] Poulsen H F, Neumann H-B, Schneider J R, Neuefeind J and Zeidler M D 1995 J. Non-Cryst. Solids 18863

[18] Paalman H H and Pings C J 1962 J. Appl. Phys. 332635

[19] Klementev K V 2001 J. Phys. D: Appl. Phys. 34209

[20] McGreevy R L and Pusztai L 1988 Mol. Simul. 1359

[21] Gereben O, Jóvári P, Temleitner L, Pusztai L 2007 J. Optoelectron. Adv. Mater. 93021

[22] Jóvári P, Saksl K, Pryds N, Lebech B, Bailey N P, Mellergård A, Delaplane R G and Franz H 2007 Phys. Rev. B 76, 054208

[23] Gruner S, Marczinke J, Hennet L, Hoyer W and Cuello G J 2009 J. Phys.: Condens. Matter 21 385403

[24] Kaban I, Jóvári P, Stoica M, Eckert J, Hoyer W and Beuneu B 2009 Phys. Rev. B 79 (2009) 212201

[25] http://www.szfki.hu/ nphys/rmc++/opening.html

[26] Ankudinov A L, Ravel B, Rehr J J and Conradson S D 1998 Phys. Rev. B 587565

[27] Michalik S, Saks1 K, Sovák P, Csach K, Jiang J Z 2009 J. Alloys and Comp. 478441 
Table 1. Mean interatomic distances $r_{\mathrm{ij}}$ and coordination numbers $N_{\mathrm{ij}}$ for $\mathrm{Zr}_{60} \mathrm{Cu}_{20} \mathrm{Fe}_{20}$ metallic glass. The error of $r_{\mathrm{ij}}$ is about $0.02 \AA$. The uncertainty of $N_{\mathrm{ij}}$ is about $10 \%$. The structural parameters of $\mathrm{Zr}_{65} \mathrm{Cu}_{35}$ metallic glass [11] are given for comparison.

\begin{tabular}{|l|l|l|l|l|l|l|}
\hline Pairs & $\begin{array}{l}\mathrm{Zr}_{60} \mathrm{Cu}_{20} \mathrm{Fe}_{20} \\
\text { metallic glass } \\
\text { This study } \\
\text { Model 1 }\end{array}$ & \multicolumn{2}{l|}{$\begin{array}{l}\mathrm{Zr}_{60} \mathrm{Cu}_{20} \mathrm{Fe}_{20} \\
\text { metallic glass } \\
\text { This study } \\
\text { Model 2 }(20 \% \\
\text { demixing })\end{array}$} & \multicolumn{2}{l|}{$\begin{array}{l}\mathrm{Zr}_{65} \mathrm{Cu}_{35} \text { metallic } \\
\text { glass [11] }\end{array}$} \\
\cline { 2 - 7 } & $r_{\mathrm{ij}}(\AA)$ & $N_{\mathrm{ij}}$ & $r_{\mathrm{ij}}(\AA)$ & $N_{\mathrm{ij}}$ & $r_{\mathrm{ij}}(\AA)$ & $N_{\mathrm{ij}}$ \\
\hline $\mathrm{Zr}-\mathrm{Zr}$ & 3.17 & 8.9 & 3.17 & 9.2 & 3.16 & 9.4 \\
\hline $\mathrm{Zr}-\mathrm{Cu}$ & 2.78 & 2.3 & 2.78 & 2.3 & 2.80 & 3.7 \\
\hline $\mathrm{Zr}-\mathrm{Fe}$ & 2.67 & 2.0 & 2.67 & 2.1 & & \\
\hline $\mathrm{Cu}-\mathrm{Zr}$ & 2.78 & 7.0 & 2.78 & 6.8 & 2.80 & 6.9 \\
\hline $\mathrm{Cu}-\mathrm{Cu}$ & 2.60 & 2.0 & 2.60 & 1.9 & 2.63 & 4.6 \\
\hline $\mathrm{Cu}-\mathrm{Fe}$ & 2.57 & 2.0 & 2.57 & 1.8 & & \\
\hline $\mathrm{Fe}-\mathrm{Zr}$ & 2.67 & 6.0 & 2.67 & 6.4 & & \\
\hline $\mathrm{Fe}-\mathrm{Cu}$ & 2.57 & 2.0 & 2.57 & 1.8 & & \\
\hline Fe-Fe & 2.53 & 1.7 & 2.53 & 1.6 & & \\
\hline
\end{tabular}



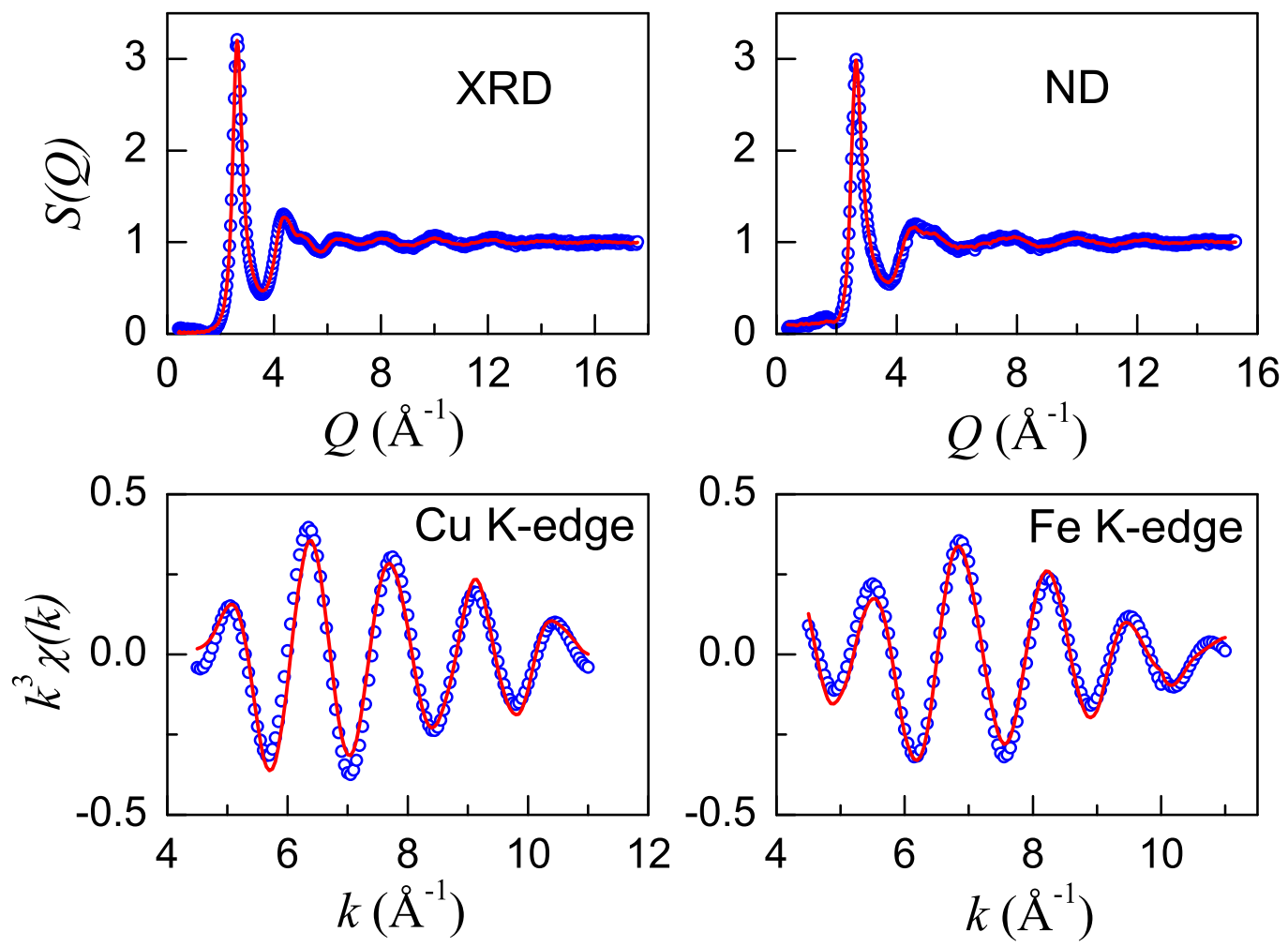

Figure 1. XRD and ND structure factors, and EXAFS spectra for $\mathrm{Zr}_{60} \mathrm{Cu}_{20} \mathrm{Fe}_{20}$ metallic glass: circles experimental data, lines - obtained by simultaneous RMC modelling of four measurements using Model 1. 

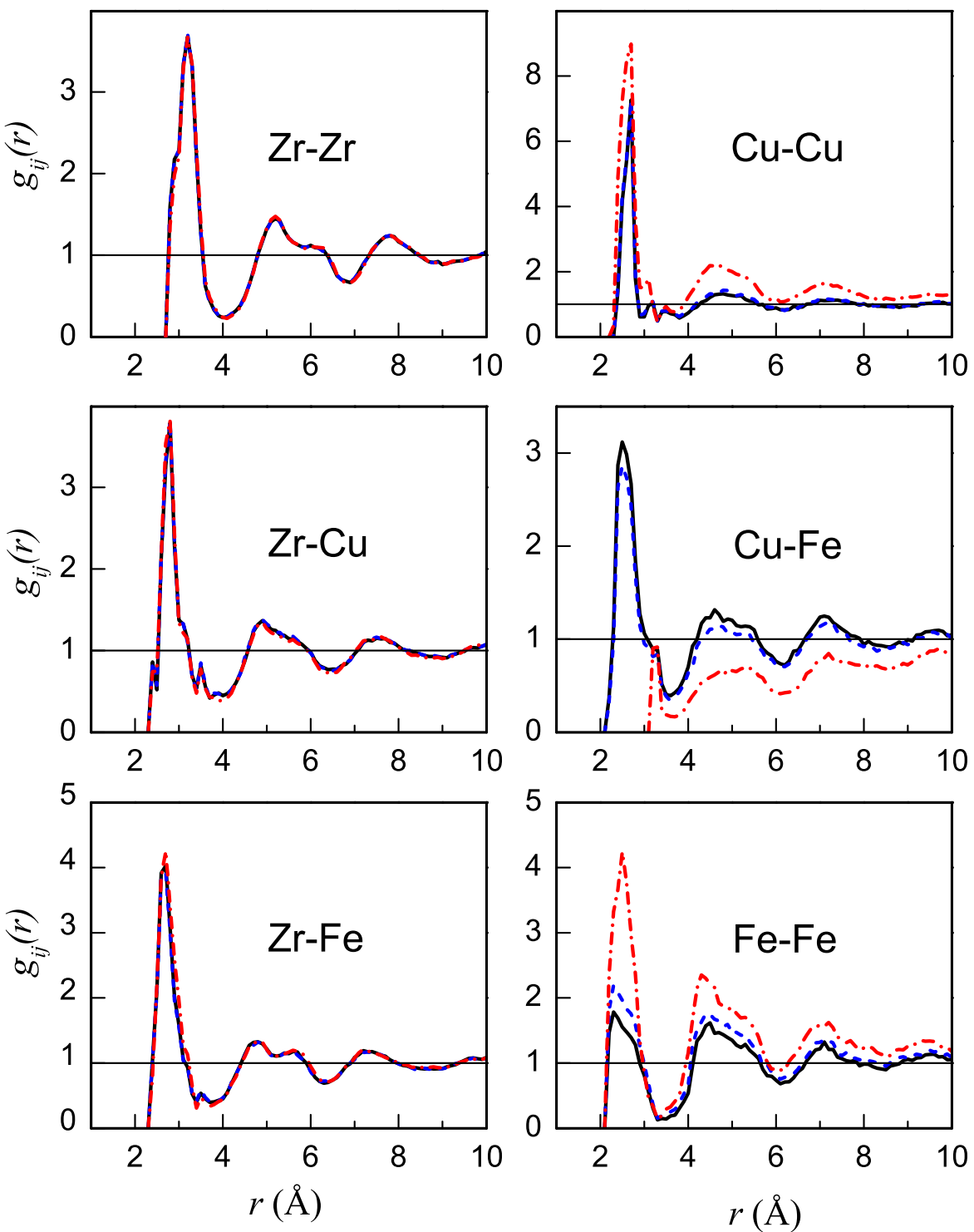

Model 1; -....-. Model 2;

Model 3

Figure 2. Partial pair distribution functions for the $\mathrm{Zr}_{60} \mathrm{Cu}_{20} \mathrm{Fe}_{20}$ composition extracted from the RMC final simulation boxes obtained with different models. Model 1 (full line) - all bonds are allowed, no coordination constraints are applied. Model 2 (dashed line) - all bonds are allowed; coordination constraint: $20 \%$ of $\mathrm{Zr}$ atoms have only $\mathrm{Cu}$ neighbours and $20 \%$ of $\mathrm{Zr}$ atoms have only Fe neighbours. Model 3 (dash-dotted line) - $\mathrm{Cu}-\mathrm{Fe}$ bonds are forbidden. The $\mathrm{Cu}-\mathrm{Cu}, \mathrm{Cu}-\mathrm{Fe}$ and $\mathrm{Fe}-\mathrm{Fe}$ partial pair distribution functions get an unphysical shape if direct $\mathrm{Cu}-\mathrm{Fe}$ bonds are forbidden. 